\title{
施钙对酸性红壤花生根系内生细菌群落结构的影响
}

\author{
张 玮 ${ }^{1}$ 洪艳云 ${ }^{1}$ 刘登望 $^{2}$ 张博文 $^{2}$ 易图永 ${ }^{1, *}$ 李 林 ${ }^{2, *}$
}

1 湖南农业大学植物保护学院 / 植物病虫害生物学与防控湖南省重点实验室, 湖南长沙 $410128 ;{ }^{2}$ 湖南农业大学旱地作物研究所, 湖南长沙 410128

摘 要: 花生是我国重要的油料作物, 也是嗜钙作物。为了探讨施钙对种植在酸性红壤下的花生根系内生细菌多样 性的影响, 本研究对不同处理、不同生育期的花生植株根系内生细菌基因组进行 16SrRNA 基因 V3-V4 区深度测序, 分析种植于酸性红壤中施钲处理和对照下花生植株根系微生物群落结构。结果发现, 根系内生菌群落中克雷伯氏菌 属(Klebsiella)与肠杆菌属(Enterobacter)在所有样品组中均为优势属且相对丰度较高; 花针期不同处理下假单胞菌属 (Pseudomonas)与赖氨酸芽狍杆菌属(Lysinibacillus)在施钙组中相对丰度显著高于对照组, 而劳尔氏属(Ralstonia)的相 对丰度在施钙组中显著降低; Network 共发生网络分析显示, 施钙组根系内生菌的网络连接相对紧密。综上结果表明, 花生根系内生菌群落组成受施钲处理和植株生长发育共同影响, 施钲能改变根系内生菌群落结构, 提高花生植株应 对病原菌侵袭。所得结果为今后通过施钙改良酸性土壤品质进而提高花生植株抗病能力提供了理论参考。

关键词: 花生; 钙; 酸性红壤; 内生细菌; 微生物多样性;

\section{Effects of calcium application on the structural diversity of endophytic bacte- rial community in peanut roots under acidic red soil cultivation}

\author{
ZHANG Wei ${ }^{1}$, HONG Yan-Yun ${ }^{1}$, LIU Deng-Wang ${ }^{2}$, ZHANG Bo-Wen $^{2}$, YI Tu-Yong ${ }^{1, *}$, and LI Lin ${ }^{2, *}$ \\ ${ }^{1}$ College of Plant Protection, Hunan Agricultural University / Hunan Provincial Key Laboratory for Biology and Control of Plant Pests, Changsha \\ 410128, Hunan, China; ${ }^{2}$ Institute of Dryland Crops of Hunan Agricultural University, Changsha 410128, Hunan, China
}

\begin{abstract}
Peanut is an important economic crop and calcium-loving crop in China. In order to explore the effect of calcium application on the diversity of endophytic bacteria in peanut roots planted in acid red soil, the genomes of endophytic bacteria in peanut roots of different treatments and different growth stages were deeply sequenced by 16SrRNA gene V3-V4 region, and the root microbial community structure of peanut plants planted in acid red soil and control was analyzed. The results showed that Klebsiella and Enterobacter were the dominant genera with high relative abundance in the endophytic bacterial community from all sample groups. The relative abundance of Pseudomonas and Lysinibacillus were significantly higher than that from the control group, while the relative abundance of Ralstonia decreased significantly in the calcium application groups during the pod-pin stage at $P \leq 0.05$. The interaction network analysis showed that the connection of root endophytic bacterial in calcium application group was relatively close. We reasonably inferred that the composition of peanut root endophytic bacterial community was affected by calcium application and plant growing development. Calcium application could change the community structure and improve the ability of peanut to cope with external stress. This study may lay a foundation for improving the quality of acid soil and improving the disease resistance of peanut by applying calcium in the future.
\end{abstract}

Keywords: peanut; calcium; acid red soil; endophytic bacteria; microbial diversity;

花生(Arachis hypogaea L.)是一种重要的油料作 物, 在我国境内广泛种植 ${ }^{[1]}$ 。然而我国花生主产区受 海洋大气环流影响, 降雨量高, 钙素极易流失, 从
而导致土壤酸化缺钲 ${ }^{[2]}$ 。花生是嗜钙作物, 缺钙会影 响果实发育, 形成空壳, 造成减产甚至绝收 ${ }^{[3]}$, 严重 影响经济效益 ${ }^{[4-6]}$ 。同时缺钙容易诱发籽仁生理病变

\section{本研究由国家重点研发计划项目(2018YFD1000900)资助。}

This study was supported by the National Research and Development Program of China (2018YFD1000900).

*通信作者(Corresponding authors): 易图永, E-mail: yituyong@hunau.net; 李林, E-mail: 1ilindw@163.com 
使之更易感染真菌病害。在植物与病原菌互作过程 中, 钙参与植物的防御反应和组织结构的形成, 增 强植物细胞稳定性和抗病能力 ${ }^{[7]}$ 。钙能直接抑制病 原菌菌丝生长、孢子萌发、附着胞形成等, 甚至能 参与病原真菌的致病性调控 ${ }^{[8-11]}$ 。

近期研究表明, 微生物菌群可以影响植物和病 原物之间的相互作用, 有益微生物能够促进植物的 生长, 同时增加植物对非生物胁迫的耐受性 ${ }^{[12]}$ 。许 多根际促生菌能够增强宿主抵抗病原物的能力, 通 过诱导系统抗性(induced systemic resistance, ISR) 使地上部分能抵抗病原微生物的侵袭和害虫的取 食 ${ }^{[13-14]}$ 。同时植物根系分泌物也能通过改变土壤理 化性质吸引附近土壤环境微生物向根部聚集, 进而 影响根际微生物的群落结构 ${ }^{[15]}$ 。Yuan 等 $^{[16]}$ 证实, 拟 南芥在受到叶部病原菌丁香假单胞菌番茄致病变种 (Pseudomonas syringae pv. tomato, Pst)侵染后, 可通 过增加氨基酸和长链有机酸分泌量等途径改变根系 分泌物成分, 从而调控土壤微生物群落来加强自身 抵御病害的能力。Molina 等 ${ }^{[17]}$ 通过将恶臭假单胞菌 (Pseudomonas putida)、鞘氨醇单胞菌(Sphingomonas sp.)、巴西固氮螺菌(Azospirillum brasilense)以及不动 杆菌(Acinetobacter sp.)的混合菌群接种至玉米根部, 从而提高了玉米的抗旱性。Berendsen 等 ${ }^{[14]}$ 用活体营 养型卵菌拟南芥无色霜霉菌 (Hyaloperonospora arabidopsidis)侵染拟南芥叶片后，通过促进根际 3 种特异诱导 ISR 的细菌增殖, 起到抗霜霉病的作用。 这些研究进一步证实了接种微生物混合种比单一菌 株在抵御病害与应对胁迫上具有更好的效果。

目前, 植物与微生物互作的研究大多数基于模 式生物拟南芥或者水稻、玉米等主要粮食作物, 而 对花生根系内生菌群落结构鲜有报道。本研究通过 对不同钙处理下花生根系内生菌的群落基因组进 行 16SrRNA 基因 V3-V4 区测序, 试图探析对钙敏 感花生植株在酸性低钙条件下，施钙处理对其根系 微生物群落结构的影响, 为合理施用矿质营养元 素、改良酸性土壤品质、降低花生病害发生提供理 论依据。

\section{1 材料与方法}

\section{1 供试材料}

试验地点为湖南农业大学耘园科研基地。花生 采用国家主推的大籽品种湘花 2008, 由湖南农业大 学旱地作物研究所选育, 对钙敏感; 酸性低钙土壤
取自湖南省汶阳市普迹镇书院村月光坪的第四纪红 壤表层土, $\mathrm{pH} 4.5$, 含有机质 $27.3 \mathrm{~g} \mathrm{~kg}^{-1}$ 、全氮 $(\mathrm{N})$ $0.82 \mathrm{~g} \mathrm{~kg}^{-1}$ 、全磷 (P) $0.33 \mathrm{~g} \mathrm{~kg}^{-1}$ 、全钾 $(\mathrm{K}) 17 \mathrm{~g} \mathrm{~kg}^{-1}$ 、 碱解氮 $(\mathrm{N}) 64 \mathrm{mg} \mathrm{kg}^{-1}$ 、速效钾 $(\mathrm{K}) 82 \mathrm{mg} \mathrm{kg}^{-1}$ 、阳离 子交换量 $13 \mathrm{cmol}(+) \mathrm{kg}^{-1}$ 、交换性钙 $(\mathrm{Ca}) 0.74 \mathrm{cmol}$ $\left(1 / 2 \mathrm{Ca}^{2+}\right) \mathrm{kg}^{-1}$ 、交换性镁 $(\mathrm{Mg}) 0.13 \mathrm{cmol}\left(1 / 2 \mathrm{Mg}^{2+}\right)$ $\mathrm{kg}^{-1}$ 、有效锌 $(\mathrm{Zn}) 0.63 \mathrm{mg} \mathrm{kg}^{-1}$ 、有效硫 $(\mathrm{S}) 143.7 \mathrm{mg}$ $\mathrm{kg}^{-1}$ 、有效硼(B) $0.12 \mathrm{mg} \mathrm{kg}^{-1}$ 、有效钼(Mo) $0.08 \mathrm{mg}$ $\mathrm{kg}^{-1}$, 有效磷 $(\mathrm{P})$ 未检出, 为典型酸性缺钙红壤(依发 明专利“花生种质钙敏感性的土壤鉴定方法” 进行 土壤鉴定，具体鉴定方法详见专利附录)。

选取内径 $36 \mathrm{~cm}$ 、高 $75 \mathrm{~cm}$ 、壁厚度 $0.5 \mathrm{~cm}$ 的 PVC 管组装成塑料大桶, 一端置于地膜之上以防止 供试土壤与试验地原有土壤接触。每桶内装供试土 壤 $90 \mathrm{~kg}$ 。施钙组每桶施加生石灰 $(\mathrm{CaO}) 12.5 \mathrm{~g}$ (125 $\mathrm{kg} \mathrm{hm}^{-2}$ ), 与桶中表层供试土壤充分混匀, 对照组不 施加生石灰 $(\mathrm{CaO})$ 。为保证除钙以外的其他基本养分 平衡一致的供给, 本试验除进行施钙及对照处理外, 各样品组其他养分均依临界值进行养分平衡: 于土 柱表层 0 20 cm 处, 参照大田标准( $45 \%$ 氮磷钾等比 例复合肥 $750 \mathrm{~kg} \mathrm{hm}^{-2}$ ) 每桶施尿素 $4.02 \mathrm{~g}$ 、磷酸二氢 钾 $8.23 \mathrm{~g}$ 及六水氯化镁 $8.50 \mathrm{~g}$, 并混匀。施钙组与对 照组各相同处理 10 桶作为重复。依十字将大桶划分 为 4 个区域，每桶定苗 4 株(作为不同生育期采集检 测样本), 始花期每桶喷施等量硼肥。花生生长发育 阶段进行正常的水分和病虫草害的管理。

\section{2 试验方法}

1.2.1 样品采集及处理 分别于苗期(2019-0604)、花针期(2019-06-24)与饱果期(2019-08-14)采集 施钙组与对照组植株根系样品。每组设置 3 个重复。 将各组样品植株全株拔出，抖动根系以去除疏松的 大块土壤。用 2 把无菌剪刀分别在施钙组与对照组 样品根茎交界处正下方切下约 $5 \mathrm{~cm}$ 的根。抖落大块 土壤，并用灭菌毛刷清除表面小颗粒状土壤，再用 无菌水多次反复冲洗样本表面, 并摘去小侧根。将 处理后的根放入 $5 \%$ 次氯酸钠溶液浸泡 $5 \mathrm{~min}$, 再转 移至装有适量无菌玻璃珠及无菌水的 $50 \mathrm{~mL}$ 灭菌离 心管中, 剧烈摇晃以便物理去除根表土壤微生物, 用 无菌水重复振荡冲洗 3 次。称取 $2 \mathrm{~g}$ 根系组织, 用灭 菌剪刀尽可能剪碎, 放入灭菌三角瓶, 加入 $20 \mathrm{~mL}$ 无 菌的 $1 \times$ PBS 缓冲液, 摇床振荡 $4 \mathrm{~h}, 40 \mathrm{KHz}$ 超声波超 声振荡 $15 \mathrm{~min}, 5 \mu \mathrm{m}$ 滤膜真空抽滤。将滤液 $15,000 \times g$ 离心 $15 \mathrm{~min}$, 弃上清收集菌体沉淀。使用 EasyPure 
Genomic DNA Kit 试剂盒提取菌体沉淀中的根系内生 细菌基因组 DNA，使用 NanoDrop2000 检测所提样品
的核酸质量, 合格后送天津诺禾致源生物信息科技有 限公司进行 $16 \mathrm{~S}$ 扩增子测序, 样品编号如表 1 所示。

表 $116 S$ 扩增子测序样品分组编号

Table 1 Group number of $16 \mathrm{~S}$ amplicon sequencing sample

\begin{tabular}{lcc}
\hline \multicolumn{1}{c}{ 生育期 } & $\begin{array}{c}\text { 不施钙组送样编号 } \\
\text { Stage }\end{array}$ & $\begin{array}{c}\text { 施钙组送样编号 } \\
\text { Sample groups without calcium application }\end{array}$ \\
\hline 苗期 Seeding stage & B.R.1, B.R.2, B.R.3 & BC.R.1, BC.R.2, BC.R.3 \\
花针期 Acicula forming stage & F.R.1, F.R.2, F.R.3 & FC.R.1, FC.R.2, FC.R.3 \\
饱果期 Pod maturing stage & P.R.1, P.R.2, P.R.3 & PC.R.1, PC.R.2, PC.R.3 \\
\hline
\end{tabular}

1.2.216S 扩增子测序取适量样本 DNA于离心 管中, 使用无菌水稀释样本至 $1 \mathrm{ng} \mu \mathrm{L}^{-1}$, 以稀释后 的基因组 DNA 为模板，根据测序区域 $16 \mathrm{~S} \mathrm{~V} 3-\mathrm{V} 4$ 选 择特异引物 $341 \mathrm{~F}$ (Forward primer 5'-CCTAYG GGRBGCASCAG-3')与 806R (Reverse primer 5'-GG ACTACNNGGGTATCTAAT-3')进行 PCR。PCR 产物 使用 $2 \%$ 浓度的琼脂糖凝胶进行电泳检测后使用 GeneJET 试剂盒纯化回收目标条带。使用 Ion Plus Fragment Library Kit 试剂盒进行文库构建。构建好 的文库经质检合格后使用 Thermofisher 的 Ion S5 XL 进行上机测序, 对测序后下机的原始数据进行拼接 和过滤, 得到 Clean Reads。

\subsubsection{OTUs 聚类分析 默认以 $97 \%$ 的一致性} (Identity) 对 Clean Reads 进行 OTUs (operational Taxonomic units)聚类, 然后通过与数据库 Silva132 的比对进行物种注释。分析微生物群落结构差异并 绘制差异 OTUs 韦恩图、UPGMA 聚类树及属水平 下物种相对丰度柱形图。选取属分类水平下 Top 40 优势物种, 使用 SPSS 软件对施钙处理与对照下不 同生育期各物种相对丰度差异进行独立样品 $\mathrm{T}$ 检验 统计分析，显著差异的分析结果使用 OriginPro 2019 软件绘制柱状图。

1.2.4 LEfSe 分析 LEfSe (LDA effect size)是一 种用于发现和解释高维度生物标识(基因、通路和分 类单元)的分析工具, 它强调统计意义和生物相关性, 能够在组与组之间寻找具有统计学差异的 Biomarker，让研究人员能够识别不同丰度的特征以 及相关联的类别, 以便找出哪些核心菌群引起组间 群落的显著差异。本研究以 3 作为 LDA Score 的篮 选值对各样品组测序数据进行 LEfSe 分析并绘制进 化分支图。在进化分支图中, 由内至外辐射的圆圈 代表了由门至属(或种)的分类级别。在不同分类级别 上的每一个小圆圈代表该水平下的一个分类，小圆
圈直径大小与相对丰度大小呈正比。着色原则为无 显著差异的物种统一着色为黄色, 差异物种 Biomarker 跟随组进行着色。

1.2.5 共发生网络构建 分别对施钙组与对照组 样品中相对丰度排名 Top100 的微生物属进行 Pearson 相关系数计算, 以优势微生物属作为核心节点, 选取 Pearson 相关系数大于 0.6 或小于-0.6 且显著差异 $(P<0.05)$ 的连接作为有效连接, 使用 Cytoscape 软件进 行共发生网络图绘制, 以便更加清晰的看出不同样品 组中某个微生物属和其他微生物的关联状况。

\section{2 结果与分析}

\section{1 根系微生物基因组 16S V3-V4 的 PCR 扩增 结果}

以稀释后基因组 DNA 为模板, 选择 $16 \mathrm{~S} \mathrm{V3-V4}$ 的特异引物 341F (5'-CCTAYGGGRBGCASCAG-3') 与 806R (5'-GGACTACNNGGGTATCTAAT-3')进行 PCR 扩增。部分样品基因组特异引物扩增后电泳检 测结果如图 1 所示。

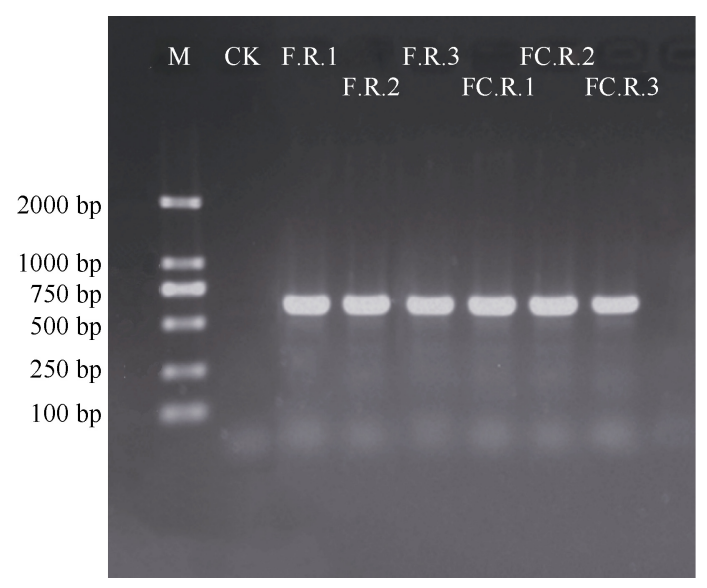

图 1 根系内生菌基因组 16S V3-V4 的 PCR 扩增电泳图

Fig. 1 PCR electrophoresis detection of $16 \mathrm{~S}$ V3-V4 from endophytic bacteria genome

样品编号同表 1 。Sample groups are the same as those given in Table 1. 


\section{$2.216 \mathrm{~S}$ 扩增子测序数据分析}

2.2.1 OTU 聚类及物种注释概况 经过物种注 释及对不同分类层级统计分析发现, 共有 2378 个 OTUs, 其中能够注释到数据库的 OTUs 数目为 2372 $(99.75 \%)$, 在门水平上, 发现占据主导地位的物种 包括厚壁菌门 (Firmicutes)、变形菌门 (Proteobacteria)、蓝藻门(Cyanobacteria)、拟杆菌门 (Bacteroidetes)及放线菌门(Actinobacteria); 在纲水 平上主要有芽孢杆菌纲 (Bacilli)、 $\gamma$-变形菌纲 (Gammaproteobacteria)、梭菌纲(Clostridia)、 $\alpha$-变形 菌纲 (Alphaproteobacteria)及拟杆菌纲 (Bacteroidia); 在目水平上的优势物种为芽孢杆菌目 (Bacillales)、肠 杆菌目(Enterobacteriales)、根瘤菌目(Rhizobiales)、 梭菌目 (Clostridiales) 以及黄单胞菌目 (Xanthomonadales); 在科水平上的主要物种为芽狍
杆菌科(Bacillaceae)、肠杆菌科(Enterobacteriaceae)、 伯克氏菌科 (Burkholderiaceae) 、根瘤菌科 (Rhizobiaceae)及黄单胞菌科(Xanthomonadaceae)。

2.2.2 花生根系内生菌群落结构为分析不同生 育期花生根系内生细菌的群落结构, 研究不同样本组 之间的相似性, 本研究通过对样本以 Binary Jaccard 距 离矩阵进行 UPGMA 等级聚类, 构建样本的聚类树。 同时根据聚类得到的 OTUs 分析不同样本组之间共有 及特有的 OTUs 并绘制成韦恩图, 如图 2 所示。根据 差异 OTUs 韦恩图分析可以发现, 除 43 个共有的核心 OTUs 以外, 随着花生植株的生长发育, 各生育期特有 的 OTUs 逐渐减少: 苗期施钙与不施钙样品组特有的 OTUs 数目为 $177 、 117$; 花针期施钲组特有 24 个差异 OTUs, 而不施钙组特有 47 个差异 OTUs; 饱果期施钙 组与对照组的差异 OTUs 数分别为 $5 、 8$ 。
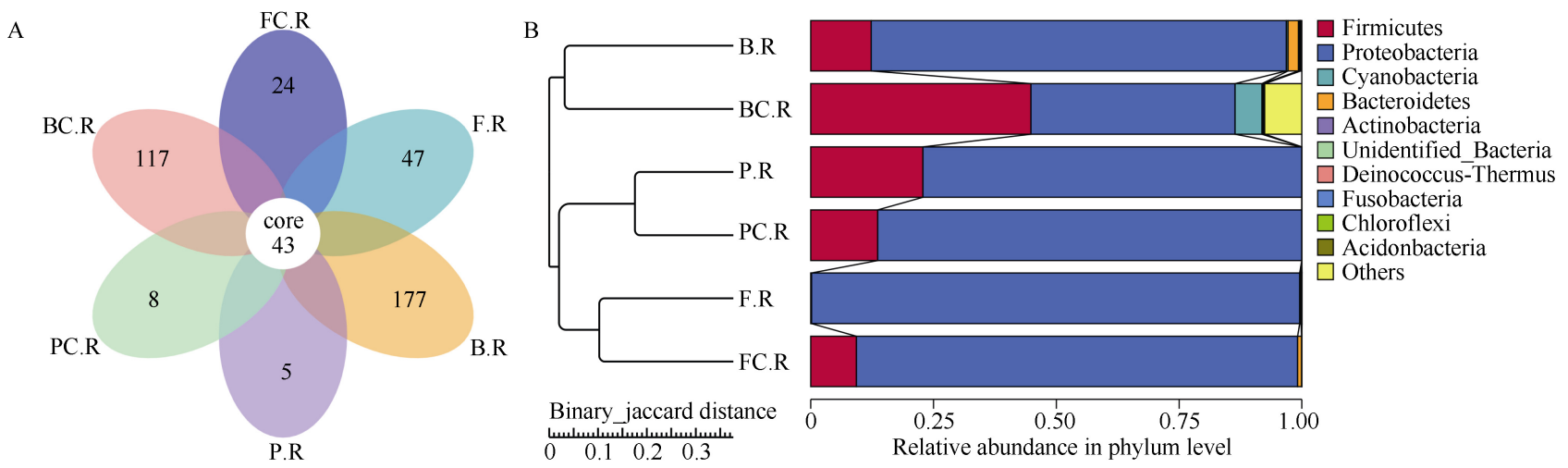

图 2 Venn 分析与 UPGMA 聚类

Fig. 2 Venn analysis and UPGMA clustering

A: 不同样品组根系内生菌差异 OTUs 韦恩图; B: 不同样品组根系内生菌 UPGMA 聚类树。样品编号同表 1。

A: Venn diagram of OTUs from the root endophytes in different sample groups; B: UPGMA clustering tree of the root endophytes in different sample groups. Sample groups are the same as those given in Table 1 .

选取不同生育期不同处理下各样品组在属 (Genus)分类水平上相对丰度排名前 20 的物种绘制 物种相对丰度柱形图, 以便直观查看各样品组中相 对丰度较高的优势物种及其所占比例(图 3)。根据测 序结果, 统计了各生育期不同处理样品组的优势物 种(相对丰度排名前 5 的优势属), 如表 2 所示。苗期 不施钙样品组优势菌属有不动杆菌属(Acinetobacter: $16.9 \%$ )、克雷伯氏菌属(Klebsiella: $16.8 \%$ )、肠杆菌 属 (Enterobacter: 7.5\%)、厌氧芽孢杆菌属 (Anoxybacillus: $5.0 \%$ )、草螺菌属 (Herbaspirillum: 4.9\%)等; 苗期施钙样品组优势菌属包括克雷伯氏菌 属(Klebsiella: $30.1 \%$ )、芽狍杆菌属(Bacillus: $26.3 \%$ )、 肠杆菌属 (Enterobacter: 6.1\%)、水栖菌属 (Enhydrobacter: 5.1\%)、慢生根瘤菌 属
(Bradyrhizobium: 1.8\%)等; 花针期不施钙样品组优 势菌属有克雷伯氏菌属(Klebsiella: 16.9\%)、肠杆菌 属(Enterobacter: $8.9 \%$ )、不动杆菌属(Acinetobacter: $6.7 \%) 、$ 泛菌属(Pantoea: $5.0 \%)$ 、戴氏菌属(Dyella: $3.7 \%$ ) 等; 花针期施钙样品组优势菌属有克雷伯氏菌 属 (Klebsiella: $37.2 \%$ ) 、寡养单胞菌属 (Stenotrophomonas: 13.1\%) 、假单胞菌属 (Pseudomonas: $8.7 \%$ )、从毛单胞菌属(Comamonas: 8.3\%)、肠杆菌属(Enterobacter： 7.4\%)等; 饱果期不 施钙样品组优势菌属为克雷伯氏菌属(Klebsiella: $33.4 \%$ )、肠杆菌属(Enterobacter: $11.3 \%$ )、类芽狍杆 菌属(Paenibacillus: 6.3\%)、假单胞菌属(Pseudomonas: 4.9\%)、芽孢杆菌属(Bacillus: 1.7\%)等; 饱果期施钙 样品组优势菌属为克雷伯氏菌属(Klebsiella: $30.9 \%$ ) 
假单胞菌属(Pseudomonas: $8.9 \%$ )、类芽狍杆菌属 (Paenibacillus: $8.7 \%$ ) 、赖氨酸芽孢杆菌属 (Lysinibacillus: $8.3 \%$ )、芽狍杆菌属(Bacillus: $3.2 \%$ ) 等; 部分主要优势物种未鉴定到属分类水平，如伯 克氏菌科 (Burkholderiaceae)、根瘤菌科 (Rhizobiaceae)、梭菌目 (Clostridiales)、蓝藻门 (Cyanobacteria)等故而未列入上述不同样品组中优 势物种排名。综合各样品组数据发现, 克雷伯氏菌
属(Klebsiella)、肠杆菌属(Enterobacter)在所有样品组 中均为优势物种且相对丰度较高。

2.2.3 优势菌属差异为了寻找不同处理下不同 生育期样品组中具有显著差异的微生物属, 选取属 分类水平下 Top40 优势物种, 对施钙处理与对照下 的不同生育期各物种相对丰度差异进行独立样品 $T$ 检验 ( $T$-test)统计分析(图 4)发现, 施钙组与对照组样 品在苗期与饱果期时，虽然部分微生物属在相对丰

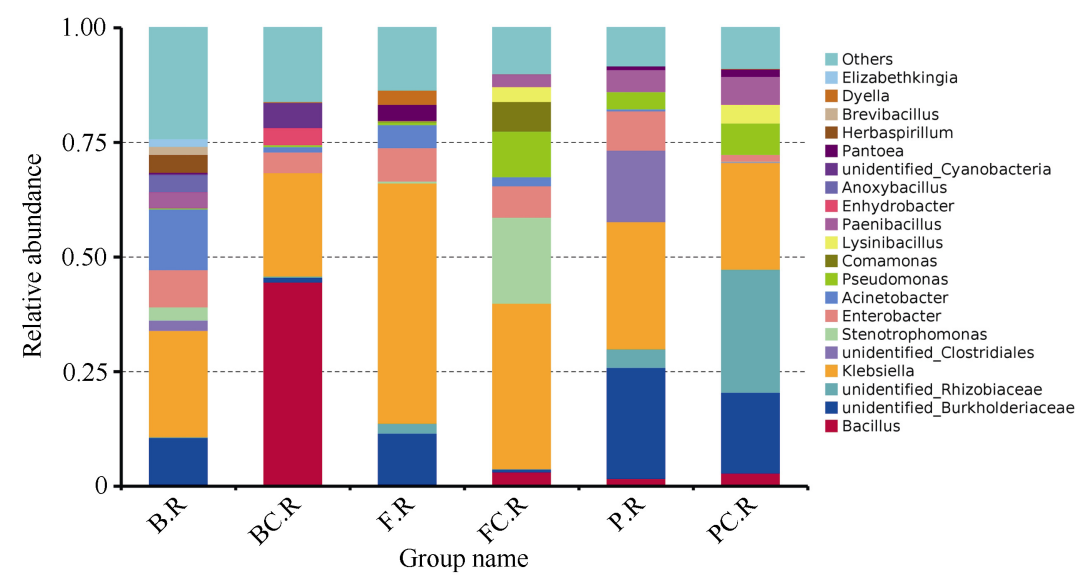

图 3 不同样品组花生根系内生菌 Top 20 物种相对丰度柱形图

Fig. 3 Histogram of the Top 20 genera relative abundance from different sample groups

样品编号同表 1。Sample groups are the same as those given in Table 1 .

表 2 属分类水平下不同生育期不同处理相对丰度百分比 Top 10 的根系内生菌

Table 2 Percentage of the Top 10 relative abundance under different growth stage and different treatments at the genus level

\begin{tabular}{|c|c|c|c|c|c|c|c|}
\hline $\begin{array}{c}\text { 处理 } \\
\text { Treatment } \\
\end{array}$ & $\begin{array}{c}\text { 样品编号 } \\
\text { Sample group }\end{array}$ & $\begin{array}{c}\text { 优势菌属 } \\
\text { Dominant genus } \\
\end{array}$ & 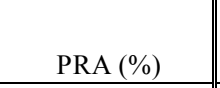 & $\begin{array}{c}\text { 处理 } \\
\text { Treatment }\end{array}$ & $\begin{array}{c}\text { 样品编号 } \\
\text { Sample group }\end{array}$ & $\begin{array}{c}\text { 优势菌属 } \\
\text { Dominant genus } \\
\end{array}$ & $\begin{array}{c}\text { 相对丰度百分比 } \\
\text { PRA }(\%) \\
\end{array}$ \\
\hline \multirow{5}{*}{$\begin{array}{c}\text { 苗期不施钙 } \\
\text { Seeding stage } \\
\text { without calcium }\end{array}$} & \multirow[t]{5}{*}{ B.R. } & Acinetobacter & 16.9 & \multirow{5}{*}{$\begin{array}{c}\text { 苗期施钙 } \\
\text { Seeding stage } \\
\text { with calcium }\end{array}$} & \multirow[t]{5}{*}{ BC.R. } & Klebsiella & 30.1 \\
\hline & & Klebsiella & 16.8 & & & Bacillus & 26.3 \\
\hline & & Enterobacter & 7.5 & & & Enterobacter & 6.1 \\
\hline & & Anoxybacillus & 5.0 & & & Enhydrobacter & 5.1 \\
\hline & & Herbaspirillum & 4.9 & & & Bradyrhizobium & 1.8 \\
\hline 花针期不施钙 & \multirow[t]{5}{*}{ F.R. } & Klebsiella & 16.9 & \multirow{5}{*}{$\begin{array}{c}\text { 花针期施钙 } \\
\text { Acicula forming } \\
\text { stage with cal- } \\
\text { cium }\end{array}$} & \multirow[t]{5}{*}{ FC.R. } & Klebsiella & 37.2 \\
\hline \multirow{4}{*}{$\begin{array}{l}\text { Acicula forming } \\
\text { stage without } \\
\text { calcium }\end{array}$} & & Enterobacter & 8.9 & & & Stenotrophomonas & 13.1 \\
\hline & & Acinetobacter & 6.7 & & & Pseudomonas & 8.7 \\
\hline & & Pantoea & 5.0 & & & Comamonas & 8.3 \\
\hline & & Dyella & 3.7 & & & Enterobacter & 7.4 \\
\hline \multirow{5}{*}{$\begin{array}{c}\text { 饱果期不施钙 } \\
\text { Pod maturing } \\
\text { stage without } \\
\text { calcium }\end{array}$} & \multirow[t]{5}{*}{ P.R. } & Klebsiella & 33.4 & \multirow{5}{*}{$\begin{array}{c}\text { 饱果期施钙 } \\
\text { Pod maturing } \\
\text { stage with cal- } \\
\text { cium }\end{array}$} & \multirow[t]{5}{*}{ PC.R. } & Klebsiella & 30.9 \\
\hline & & Enterobacter & 11.3 & & & Pseudomonas & 8.9 \\
\hline & & Paenibacillus & 6.3 & & & Paenibacillus & 8.7 \\
\hline & & Pseudomonas & 4.9 & & & Lysinibacillus & 8.3 \\
\hline & & Bacillus & 1.7 & & & Bacillus & 3.2 \\
\hline
\end{tabular}

样品编号同表 1。Sample groups are the same as those given in Table 1. PRA: percentage of the relative abundance. 
度上存在差异, 但并不显著 $(P>0.05)$, 而花针期施 钙处理与对照之间, 假单胞菌属 (Pseudomonas: $P=0.025$ )、赖氨酸芽狍杆菌属(Lysinibacillus: $P=0.037$ ) 及劳尔氏菌属(Ralstonia: $P=0.038$ )的相对丰度存在 显著差异 $(P \leq 0.05)$ 。其中假单胞菌属(Pseudomonas) 与赖氨酸芽孢杆菌属 (Lysinibacillus) 施钻组中的相 对丰度较不施钙组明显增加而劳尔氏菌属(Ralstonia) 的相对丰度则在施钙组中显著降低。前人研究发现 假单胞菌属(Pseudomonas) 与赖氨酸芽孢杆菌属 (Lysinibacillus)的部分菌株具有抑菌活性, 降解有害 物质甚至抵御病害侵袭的作用, 而劳尔氏菌属 (Ralstonia) 与花生青枯病病原菌在分类水平上为同 一属。施钙对这些优势微生物属相对丰度的显著影 响极有可能与这些菌属的生物学功能息息相关。施 钲可能在一定程度上能抑制某些病原菌生长, 从而 有利于花生抵御相关病害。

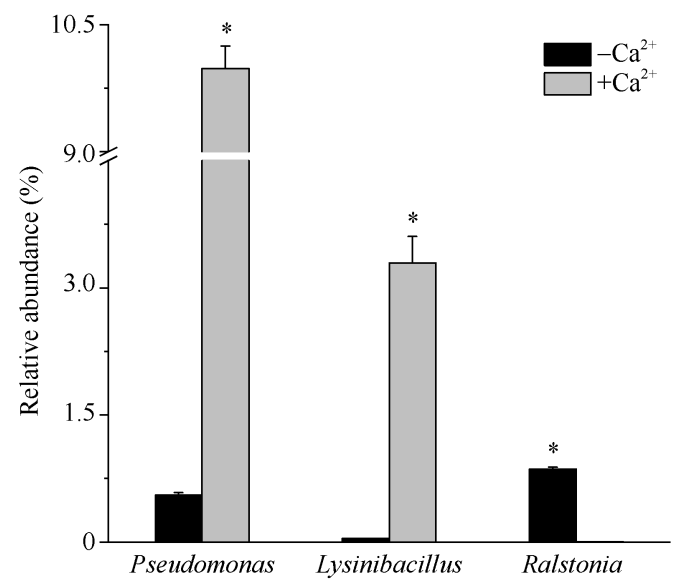

图 4 花针期相对丰度差异显著微生物属

Fig. 4 Genera with significant differences in relative abundance at acicula forming stage

LEfSe 统计分析结果如图 5 (LEfSe 进化分支图) 所示, 红色节点表示在苗期不施钙样品组中起到重 要作用的微生物类群, 绿色节点表示在苗期施钙样 品组中起到重要作用的微生物类群, 蓝色节点表示 在花针期不施钙样品组中起到重要作用的微生物类 群, 紫色节点表示在花针期施钙样品组中起到重要 作用的微生物类群, 浅蓝色节点表示在饱果期不施 钙样品组中起到重要作用的微生物类群, 橙色节点 表示在饱果期施钙样品组中起到重要作用的微生物 类群。进化分支图结果显示, 紫色扇形区域与橙色 扇形区域较大且相关节点较多, 表明花针期与饱果 期施钙样品组中能起到关键生物学作用的微生物类 群较多。属分类水平上: 施钙样品组中苗期的慢生
根瘤菌属(Bradyrhizobium), 花针期的希瓦氏菌属 (Shewanella)、假单胞菌属(Pseudomonas)及寡养单胞 菌属(Stenotrophomonas), 饱果期的类芽孢杆菌属 (Paenibacillus)、赖氨酸芽孢杆菌属(Lysinibacillus) 与短波单胞菌属(Brevundimonas)等优势物种分别在 不同的生育期起关键性生物学作用。

2.2.4 Network 共发生网络分析 网络分析被广 泛应用于复杂微生物群落的探究中。为进一步探究 不同处理下花生根系内生细菌间的相互作用，本研 究计算差异菌属两两之间 pearson 相关系数并构建 了共发生网络(图 6)。在施钙组微生物菌属共发生网 络中, 核心菌属类诺卡式菌属(Nocardioides)与 18 个 菌属显著正相关, 溶杆菌属(Lysobacter)和中生根瘤 菌属(Mesorhizobium)均与 17 个菌属显著正相关, 细 链狍菌属(Catenulispora) 与 16 个菌属显著正相关。 而相应的在不施钙处理下样品组根系内生菌关联互 作网络中, 发现核心菌属潘多拉菌属(Pandoraea)与 其他菌属之间的总关联系数最高, 而戴氏菌属 (Dyella)与 16 个菌属显著正相关。丛毛单胞菌属 (Comamonas)、罗河杆菌属(Rhodanobacter)、芽孢杆 菌属(Bacillus)、劳尔氏菌属(Ralstonia)等优势菌属也 与其他菌属之间存在不同程度的关联互作。推测在 施钙处理的花生根系内生细菌群落中, 类诺卡式菌 属(Nocardioides)、溶杆菌属(Lysobacter)、中生根瘤 菌属(Mesorhizobium)以及细链狍菌属(Catenulispora) 作为核心菌属具有重要调控作用, 且对网络内其他 微生物种群影响较大。而在不施钙处理的花生根系 内生细菌群落中, 潘多拉菌属(Pandoraea)、戴氏菌 属(Dyella)、丛毛单胞菌属(Comamonas)、罗河杆菌 属(Rhodanobacter)、芽孢杆菌属(Bacillus)、劳尔氏 菌属(Ralstonia) 等可能为该微生物群落的核心调控 菌属, 对其他微生物种群具有较大的影响。同时可 以明显看出, 以类诺卡式菌属(Nocardioides)为核心 的施钙组菌群之间互作联系更为紧密, 有效关联更 多。表明施钲能在一定程度上增强根系内生菌群之 间的互作联系, 使相互关联紧密。

\section{3 讨论}

植物根系是植物-微生物互作的重要生境场所。 在此微生态区域, 微生物更易受到植物种类、土壤 类型、植物生长阶段等多因素的影响。本研究采用 高通量测序技术，摒弃了繁琐复杂的分离纯化菌株， 以新的视角全面探究, 比较分析了施钙处理与对照 


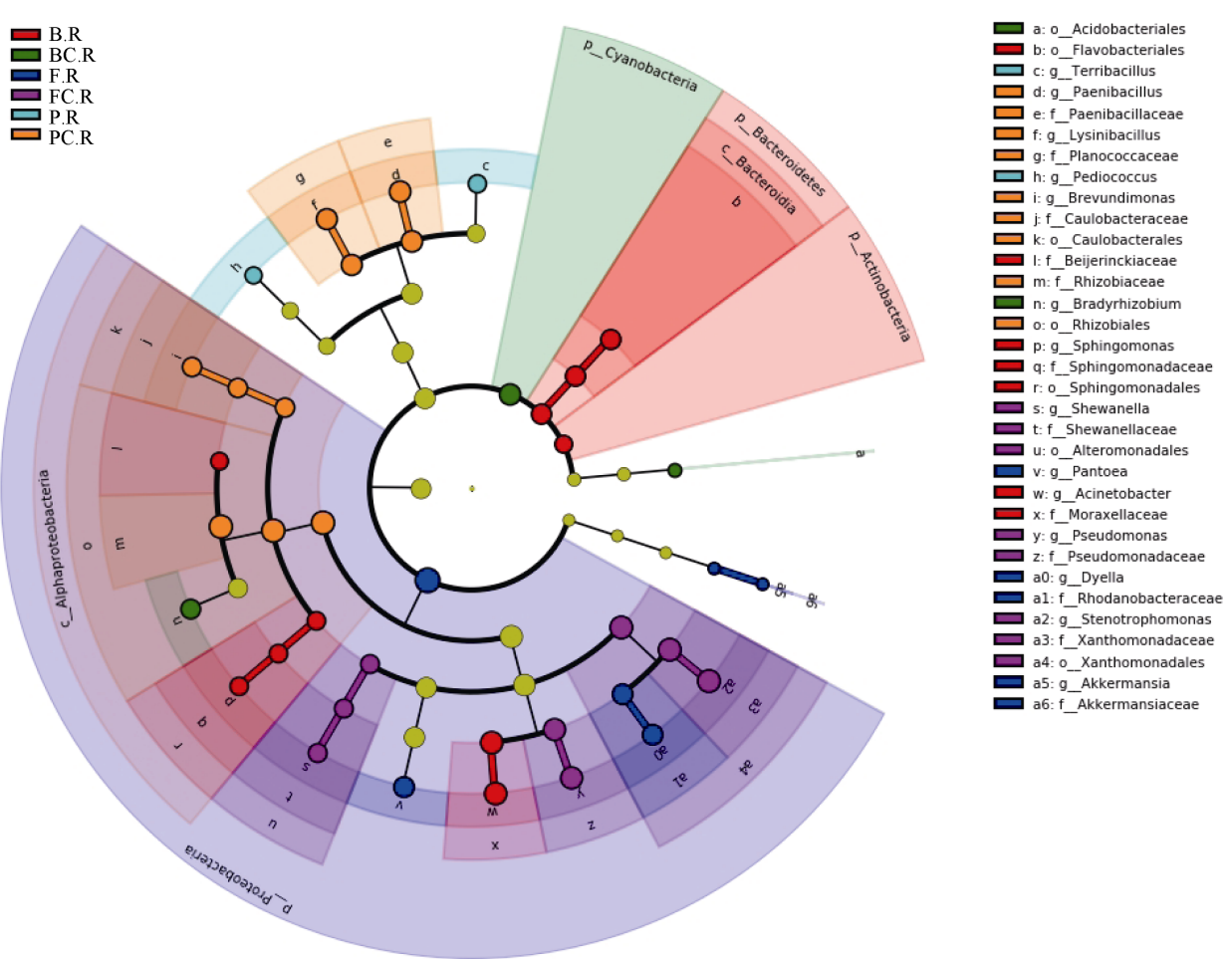

图 5 不同样品组花生根系内生菌 LEfSe 分析进化分支图

Fig. 5 LEfSe analysis cladogram of endophytic bacteria from different sample groups

样品编号同表 1。Sample groups are the same as those given in Table 1.
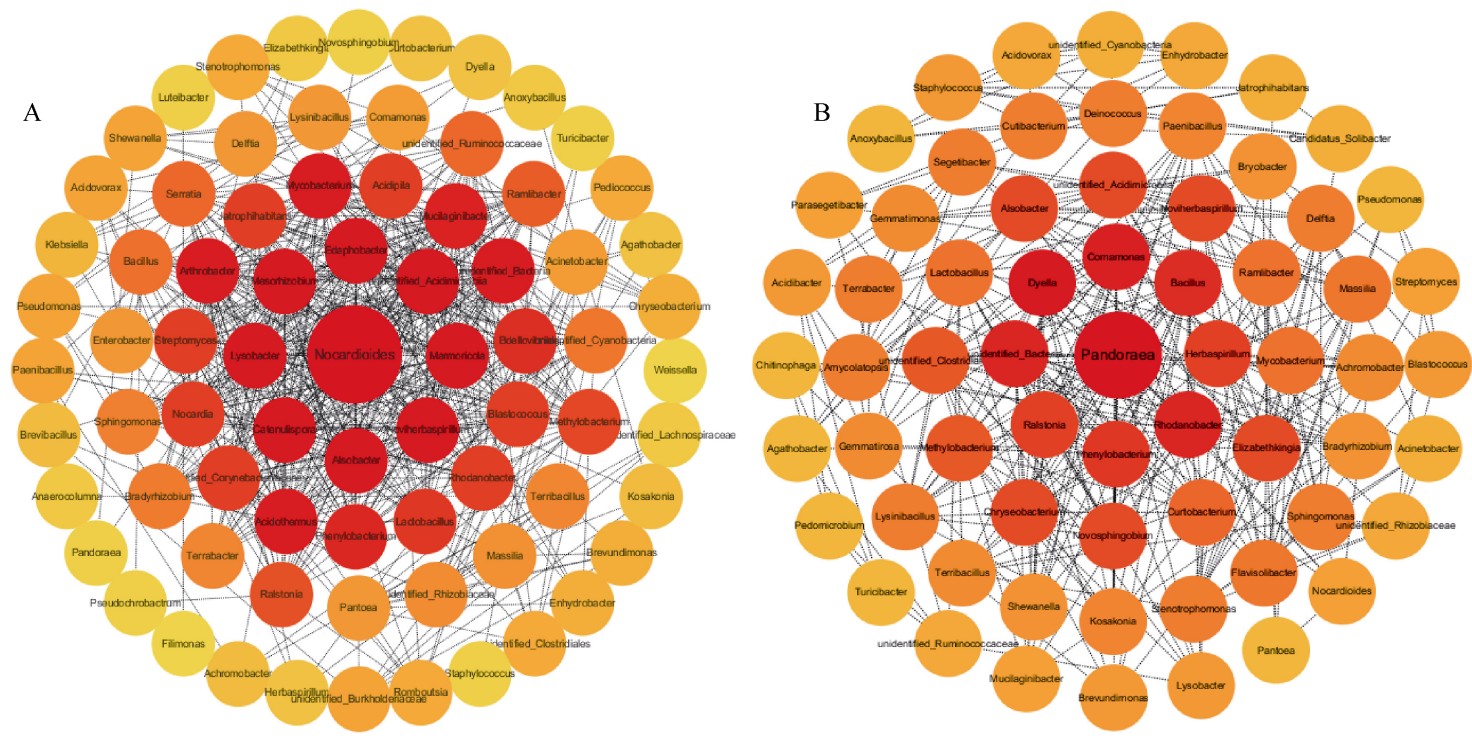

图 6 不同处理下根系内生菌共发生网络图

Fig. 6 Interaction network of endophytic bacteria under different treatments

A: 施钙样品组根系内生菌关联互作网络图; B: 不施钙样品组根系内生菌关联互作网络图。

A: interaction network of endophytic bacteria with calcium application; B: interaction network of endophytic bacteria without calcium application.

之间花生根系内生菌群落结构的显著差异：差异 OTUs 分析发现，苗期与饱果期施钙样品组中所含 根系内生细菌差异 OTUs 数显著高于不施钙样品, 即这 2 个不同生育期施钻花生样品中根系内生细菌
多样性较对照组更为丰富。优势菌属差异分析发现, 假单胞菌属(Pseudomonas) 与赖氨酸芽狍杆菌属 (Lysinibacillus) 的相对丰度在施钻组中显著增加，而 劳尔氏菌属(Ralstonia)相对丰度显著降低。克雷伯氏 
菌属(Klebsiella)、肠杆菌属(Enterobacter)、类芽狍杆 菌 属 (Paenibacillus)、寡养单胞菌 属 (Stenotrophomonas) 等优势物种作为施钙与对照组间 显著差异菌群分别在不同的生育期施钙组样品中起 关键性生物学作用。同时, 共发生网络的构建展示 出施钙能在一定程度上使根系内生细菌种群之间联 系更为紧密, 增强优势菌群之间的关联互作; 同时 分析结果还表明, 类诺卡式菌属(Nocardioides)、溶 杆菌属(Lysobacter)、细链狍菌属(Catenulispora) 等是 施钙组根系内生菌群落中的核心菌属。

Ibanez 等 ${ }^{[18]}$ 的研究发现, 克雷伯氏菌属 (Klebsiella) 能在花生根系结瘤固氮和促进植株生长, Sharm 等 ${ }^{[19]}$ 发现, 克雷伯氏菌 MBE02 (Klebsiella MBE02)能诱导花生产生 ISR 同时抵御真菌病害。 Gong 等 ${ }^{[20]}$ 的研究论述了阿氏肠杆菌 Vt-7 (Enterobacter asburiae Vt-7)对黄曲霉的抑菌活性及对黄曲 霉毒素的减毒作用，与此同时 Yang 等 ${ }^{[21]}$ 分离的苂光 假单胞菌 3JW1 (Pseudomonas fluorescens 3JW1)、 Wang 等 ${ }^{[22]}$ 发现的青岛假单胞菌新种(Pseudomonas qingdaonensis sp. nov.)、Wang 等 ${ }^{[23]}$ 首次报道的解木 糖赖氨酸芽孢杆菌(Lysinibacillus xylanilyticus)等菌 株同样具有抑制黄曲霉菌活性, 降解黄曲霉毒素或 者产生黄曲霉毒素抑制剂的作用。Haggag 等 ${ }^{[24]}$ 研究 证实, 多粘类芽孢杆菌 (Paenibacillus polymyxa) 能有 效生物防治花生冠腐病。魏兰芳等 ${ }^{[25]}$ 发现, 抗生素 溶杆菌 13-1 (Lysobacter antibioticus 13-1)菌株产生 的抗菌物质能对水稻白叶枯病具有防治效果。类诺 卡式菌属(Nocardioides)大多能降解有毒物质, 对石 油污染土壤进行生物修复, 雒晓芳等 ${ }^{[26]}$ 却分离鉴定 并探究了白色类诺卡氏菌(Nocardioides albus)对部 分病原菌的抑菌活性。云天艳等 ${ }^{[27]}$ 还从木薯根际分 离到能拮抗尖孢镰刀菌的专化型放线菌 MS13, 鉴 定后属于细链狍菌属(Catenulispora)。

结合这些以往的研究成果可以合理推测, 克雷 伯氏菌属(Klebsiella)作为所有样品组中的优势物种 在某种程度上具有结瘤固氮促进植株生长以及提高 花生产量的作用。施钙能显著增加假单胞菌属 (Pseudomonas) 与赖氨酸芽孢杆菌属(Lysinibacillus) 在根系内生菌群落中的相对丰度, 联合肠杆菌属 (Enterobacter)、类芽狍杆菌属(Paenibacillus)、寡养 单胞菌属(Stenotrophomonas)等优势物种能在一定条 件下抑制黄曲霉活性同时缓解黄曲霉毒素的毒性甚 至降低花生冠腐病的发生概率。与对照组相比, 相
对丰度显著降低的劳尔氏菌属(Ralstonia)则间接说 明施钙极有可能同时抑制花生青枯病的发生。而类 诺卡式菌属(Nocardioides)、溶杆菌属(Lysobacter)、 细链狍菌属 (Catenulispora) 等作为施钙组中的核心 菌属能对部分病原菌产生抑菌活性。

\section{4 结论}

施钙能丰富根系内生细菌群落的多样性, 使群 落间更为紧密的关联互作; 也能使根系微生物组具 有更好的促生作用，使植株能更好地抵御病害侵袭; 施钙能增强特定物种的相对丰度从而促进花生植株 的生长发育, 提高产量与品质同时可能抑制常见病 害如花生冠腐病、花生青枯病的发生, 抑制黄曲霉 菌活性甚至降解黄曲霉毒素; 这些研究结果在一定 程度上为南方酸性红壤条件下种植花生提供了施肥 管理及病害防控等方面的合理模式, 同时为如何改 良酸性土壤品质及提高花生产量与品质奠定了理论 基础。

\section{References}

[1] Zhuang W, Chen H, Yang M, Wang J, Pandey M K, Zhang C, Chang W C, Zhang L, Zhang X, Tang R, Garg V, Wang X, Tang H, Chow C N, Wang J, Deng Y, Wang D, Khan A W, Yang Q, Cai T, Bajaj P, Wu K, Guo B, Zhang X, Li J, Liang F, Hu J, Liao B, Liu S, Chitikineni A, Yan H, Zheng Y, Shan S, Liu Q, Xie D, Wang Z, Khan S A, Ali N, Zhao C, Li X, Luo Z, Zhang S, Zhuang R, Peng Z, Wang S, Mamadou G, Zhuang Y, Zhao Z, Yu W, Xiong F, Quan W, Yuan M, Li Y, Zou H, Xia H, Zha L, Fan J, Yu J, Xie W, Yuan J, Chen K, Zhao S, Chu W, Chen Y, Sun P, Meng F, Zhuo T, Zhao Y, Li C, He G, Zhao Y, Wang C, Kavikishor P B, Pan R L, Paterson A H, Wang X, Ming R, Varshney R K. The genome of cultivated peanut provides insight into legume karyotypes, polyploid evolution and crop domestication. Nat Genet, 2019, 51: 865-876.

[2] 刘鹏, 田颖哲, 钟永嘉, 廖红. 酸性土壤上花生高效根瘤菌的 分离及应用. 中国农业科学, 2019, 52: 3393-3403.

Liu P, Tian Y Z, Zhong Y J, Liao H. Isolation and application of effective Rhizobium strains in peanut on acidic soils. Sci Agric Sin, 2019, 52: 3393-3403 (in Chinese with English abstract).

[3] Li Y, Meng J, Yang S, Guo F, Zhang J, Geng Y, Cui L, Wan S, Li $\mathrm{X}$. Transcriptome analysis of calcium- and hormone-related gene expressions during different stages of peanut pod development. Front Plant Sci, 2017, 8: 1241.

[4] 王飞, 王建国, 李林, 刘登望, 万书波, 张昊. 施钙与覆膜栽 培对缺钙红壤花生 $\mathrm{Mg} 、 \mathrm{Fe} 、 \mathrm{Zn}$ 吸收、积累及分配的影响. 核 农学报, 2019, 33: 2261-2270.

Wang F, Wang J G, Li L, Liu D W, Wan S B, Zhang H. Effects of calcium application and film mulching on the absorption, accumulation and distribution of $\mathrm{Mg}, \mathrm{Fe}, \mathrm{Zn}$, in calcium-deficient red soil peanuts. J Nuclear Agric Sci, 2019, 33: 2261-2270 (in Chinese with English abstract). 
[5] 张佳蕾, 郭峰, 孟静静, 杨莎, 耿耘, 杨佃卿, 李元高, 张文生, 李新国, 万书波. 钙肥对旱地花生生育后期生理特性和产量 的影响. 中国油料作物学报, 2016, 38: 321-327.

Zhang J L, Guo F, Meng J J, Yang S, Geng Y, Yang D Q, Li Y G, Zhang W S, Li X G, Wan S B. Effects of calcium fertilizer on physiological characteristics at late growth stage and pod yield of peanut on dryland. Chin J Oil Crop Sci, 2016, 38: 321-327 (in Chinese with English abstract).

[6] 李东霞, 符海泉, 杨伟波, 徐中亮. 不同钲处理对 2 份海南花 生种质资源农艺性状和防御酶系统的影响. 江苏农业科学, 2019, 47(10): 117-121.

Li D X, Fu H Q, Yang W B, Xu Z L. Effects of different calcium treatments on agronomic characters and defense enzyme system of 2 peanut germplasm resources from Hainan. Jiangsu Agric Sci, 2019, 47(10): 117-121 (in Chinese with English abstract).

[7] Jiang J, Li J, Dong Y. Effect of calcium nutrition on resistance of tomato against bacterial wilt induced by Ralstonia solanacearum. Eur J Plant Pathol, 2013, 136: 547-555.

[8] Hosseini S A, Rethore E, Pluchon S, Ali N, Billiot B, Yvin J C. Calcium application enhances drought stress tolerance in sugar beet and promotes plant biomass and beetroot sucrose concentration. Int J Mol Sci, 2019, 20: 3777.

[9] Moeder W, Phan V, Yoshioka K. $\mathrm{Ca}^{2+}$ to the rescue- $\mathrm{Ca}^{2+}$ channels and signaling in plant immunity. Plant Sci, 2019, 279: 19-26.

[10] Zipfel C, Oldroyd G E. Plant signalling in symbiosis and immunity. Nature, 2017, 543: 328-336.

[11] 王芳, 李振轮, 陈艳丽, 杨水英, 徐义. 钙抑制植物病害作用 及机制的研究进展. 生物技术通报, 2017, 33(2): 1-7.

Wang F, Li Z L, Chen Y L, Yang S Y, Xu Y. Recent advances on inhibition mechanisms of calcium on plant diseases. Biotechnol Bull, 2017, 33(2): 1-7 (in Chinese with English abstract).

[12] 姜焕焕, 王通, 陈娜, 禹山林, 迟晓元, 王冕, 祁佩时. 根际促 生菌提高植物抗盐碱性的研究进展. 生物技术通报, 2019, 35(10): 189-197.

Jiang H H, Wang T, Chen N, Yu S L, Chi X Y, Wang M, Qi P S. Research progress in PGPR improving plant's resistance to salt and alkali. Biotechnol Bull, 2019, 35(10): 189-197 (in Chinese with English abstract).

[13] 吴晓青, 周方园, 张新建. 微生物组学对植物病害微生物防治 研究的启示. 微生物学报, 2017, 57: 867-875.

Wu X Q, Zhou F Y, Zhang X J. The enlightenment of microbiome to plant disease control. Acta Microbiol Sin, 2017, 57: 867-875 (in Chinese with English abstract).

[14] Berendsen R L, Vismans G, Yu K, Song Y, de Jonge R, Burgman W P, Burmolle M, Herschend J, Bakker P, Pieterse C. Disease-induced assemblage of a plant-beneficial bacterial consortium. ISME J, 2018, 12: 1496-1507.

[15] 韩丽珍, 刘畅, 周静. 接种促生菌对花生根际土壤微生物及营 养元素的影响. 基因组学与应用生物学, 2019, 38: 3065-3073.

Han L Z, Liu C, Zhou J. Effects of inoculation with growth-promoting bacteria on peanut rhizosphere soil microorganism and nutrient elements. Genomics Appl Biol, 2019, 38: 3065-3073 (in Chinese with English abstract).

[16] Yuan J, Zhao J, Wen T, Zhao M, Li R, Goossens P, Huang Q, Bai
Y, Vivanco J M, Kowalchuk G A, Berendsen R L, Shen Q. Root exudates drive the soil-borne legacy of aboveground pathogen infection. Microbiome, 2018, 6: 156.

[17] Molina-Romero D, Baez A, Quintero-Hernandez V, Castaneda-Lucio M, Fuentes-Ramirez L E, Bustillos-Cristales M, Rodriguez-Andrade O, Morales-Garcia Y E, Munive A, Munoz-Rojas J. Compatible bacterial mixture, tolerant to desiccation, improves maize plant growth. PLoS One, 2017, 12: e187913.

[18] Ibáñez F, Angelini J, Taurian T, Tonelli M L, Fabra A. Endophytic occupation of peanut root nodules by opportunistic Gammaproteobacteria. Syst Appl Microbiol, 2009, 32: 49-55.

[19] Sharma S, Chen C, Navathe S, Chand R, Pandey S P. A halotolerant growth promoting rhizobacteria triggers induced systemic resistance in plants and defends against fungal infection. Sci Rep, 2019, 9: 4054.

[20] Gong A, Dong F, Hu M, Kong X, Wei F, Gong S, Zhang Y, Zhang J, Wu A, Liao Y. Antifungal activity of volatile emitted from $E n$ terobacter asburiae Vt-7 against Aspergillus flavus and aflatoxins in peanuts during storage. Food Control, 2019, 106: 106718.

[21] Yang X, Zhang Q, Chen Z Y, Liu H, Li P. Investigation of Pseudomonas fluorescens strain 3JW1 on preventing and reducing aflatoxin contaminations in peanuts. PLoS One, 2017, 12: e178810.

[22] Wang M Q, Wang Z, Yu L N, Zhang C S, Bi J, Sun J. Pseudomonas qingdaonensis sp. nov., an aflatoxin-degrading bacterium, isolated from peanut rhizospheric soil. Arch Microbiol, 2019, 201: 673-678.

[23] Wang K, Yan P S, Ding Q L, Wu Q X, Wang Z B, Peng J. Diversity of culturable root-associated/endophytic bacteria and their chitinolytic and aflatoxin inhibition activity of peanut plant in China. World J Microbiol Biotechnol, 2013, 29: 1-10.

[24] Haggag W M, Timmusk S. Colonization of peanut roots by biofilm-forming Paenibacillus polymyxa initiates biocontrol against crown rot disease. J Appl Microbiol, 2008, 104: 961-969.

[25] 魏兰芳, 周丽洪, 姬广海, 王永吉, 汪绍雪. Lysobacter antibioticus 13-1 菌株抗菌物质鉴定及对水稻白叶枯病的防治效果. 微生物学通报, 2014, 41: 274-280.

Wei L F, Zhou L H, Ji G H, Wang Y J, Wang S X. Control of rice bacterial leaf blight by antibacterial substances from Lysobacter antibioticus strain 13-1. Microbiol China, 2014, 41: 274-280 (in Chinese with English abstract).

[26] 雒晓芳, 陈俊楠, 田丹妮, 汪如婷, 马麟龙, 莫芳芳. 白色类 诺卡氏菌的分离鉴定及其抗菌活性初探. 中国酿造, 2015, 34(10): 58-61.

Luo X F, Chen J L, Tian D N, Wang R T, Ma L L, Mo F F. Separation and identification of Nocardioides albus and preliminary research on its antibacterial activity. China Brew, 2015, 34(10): 58-61 (in Chinese with English abstract).

[27] 云天艳, 冯仁军, 陈宇丰, 周登博, 高祝芬, 起登凤, 张银东, 张锡炎. 木薯根际放线菌的分离鉴定及其抑菌活性分析. 江 苏农业科学, 2016, 44(4): 166-171.

Yun T Y, Feng R J, Chen Y F, Zhou D B, Gao Z F, Qi D F, Zhang $\mathrm{Y} D$, Zhang X Y. Isolation and identification of cassava rhizosphere actinomycetes and analysis of its antibacterial activity. Jiangsu Agric Sci, 2016, 44(4): 166-171 (in Chinese with English abstract). 